\title{
Correction to: The Mth Coherent State
}

\section{Anas Othman ${ }^{1}$}

Published online: 21 June 2019

(C) Springer Science+Business Media, LLC, part of Springer Nature 2019

\section{Correction to: Int J Theor Phys https://doi.org/10.1007/s10773-019-04136-1}

The original article has been corrected. The left image of Figure 3 was previously not correct.

Publisher's Note Springer Nature remains neutral with regard to jurisdictional claims in published maps and institutional affiliations.

The online version of the original article can be found at https://doi.org/10.1007/s10773-019-04136-1

Anas Othman

aothman@taibahu.edu.sa

1 Department of Physics, Faculty of Science, Taibah University, Al Madinah Al Munawwarah, Saudi Arabia 